\title{
Pengaruh Kualitas Pelayanan Terhadap Kepuasan Nasabah Pada PD. BPR Rokan Hilir Cabang Kubu Kabupaten Rokan Hilir
}

\author{
SYAMSUDDIN HASAB \\ Sekolah Tinggi Ilmu Ekonomi Riau \\ Jln. HR Subrantas KM 12 Telp (0761) 63237 Fax (0761) 63366 \\ E-mail : doni.hasab@yahoo.com
}

\begin{abstract}
This research was conducted at PD. Loss Of Kubu Branch Rokan Hilir District. The purpose of this study was to determine the effect of service quality on customer satisfaction at Rokan Hilir BPR. The population in this study was 8,574 customers. In this study, sampling uses incidental sampling, and the sample size is 99 customers. The data used are primary and secondary data with analysis using simple linear regression. The results show that service quality has a significant effect on customer satisfaction. The magnitude of the effect of service quality on customer satisfaction is 51.5 percent while the remaining 48.5 percent describes other independent variables not observed in this study.
\end{abstract}

Keywords: Service Quality and Customer Satisfaction

Sumberdaya manusia merupakan modal utama dalam pembangunan Indonesia, pemanfaatan sumber daya tersebut tidak hanya dalam konteks bagaimana kuantitas, namun yang lebih penting adalah peningkatan kualitas sumber daya manusia, sehingga dapat menunjang tujuan pembangunan nasional.

Salah satu sarana yangmempunyai peranan strategis dalam mewujudkan pembangunan nasional dan menyeimbangkan masing- masing unsur tersebut adalah sektor perbankan. Perbankan memiliki peranan yang sangat penting yang tak bisa lepas dari pola kehidupan masyarakat, terlebih pada para prilaku ekonomi. Bank merupakan tumpuan bagi para prilaku ekonomi bahkan sektor perbankan telah menjadi mobilisator utama kegiatan perekonomian suatu negara. Adapun syarat yang harus dipenuhi oleh perbankan agar dapat sukses dalam persaingan adalah berusaha untuk menciptakan dan mempertahankan nasabah. Nasabah merupakan faktor penting bagi perkembangan suatu perusahaan, karena tanpa nasabah suatu bank tidak akan dapat menjalankan kegiatan usahanya. Salah satu faktor yang berharga dan dapat memberikan kesan yang mendalam bagi nasabah adalah memberikan kepuasan melalui kualitas pelayanan yang berdasarkan pada lima dimensi yaitu Bukti Fisik (tangibles), Keandalan (reliability), Daya Tanggap (responsiveness), Jaminan (assurance), dan Empati (empathy). Kelima dimensi kualitas jasa tersebut sangat penting diperhatikan oleh setiap perusahaan khususnya pada Bank PD.BPR Rokan Hilir Cabang Kubu

Kecamatan Kubu merupakan salah satu Kecamatan yang ada di Kabupaten Rokan Hilir. Terdapat dua Bank yang ada di Kecamatan kubu salah satunya adalah PD. Bank Perkreditan Rakyat (BPR) Rokan Hilir.Secara umum kegiatan usaha PD.BPR Rokan Hilir Cabang Kubu adalah memberikan kredit, menghimpun dana dari masyarakat dalam bentuk simpanan deposito berjangka dan tabungan.

Produk dana terbagi dalam beberapa jenis yaitu: Tabungan Gema Bahari, Tabungan Pelajar,dan Deposito, sedangkan produk pinjaman terbagi atas Kredit Modal Kerja,dan Kredit Investasi. Produk-produk diatas termasuk produk produktif, yang mana merupakan bentuk 
yang melaksanakan kegiatan usaha secara konvensional atau berdasarkan prinsip syariah. Yang dalam kegiatannya tidak memberikan jasa dalam lalu lintas pembayaran penarikannya, dimana tingkat bunganya ditetapkan oleh Bank Indonesia.

Untuk mengetahui seberapa besar tingkat perkembangan nasabah pada tabungan produktif dari tahun-ketahun yang harus meningkatkan bisa dapat dapat dijelaskan jumlah nasabah dan jumlah nominal tabungan PD.BPR Rokan Hilir Cabang Kubu 5tahun terakhir yaitu pada tahun 2013 jumlah nasabah sebanyak 5.142 orang, pada tahun 2014 sebanyak 5.994 orang, mengalami kenaikan sebanyak 852 orang atau $14,21 \%$, pada tahun 2015 jumlah nasabah sebanyak 6.838 orang mengalami kenaikan sebanyak 844 atau 12,34 \%. Pada tahun 2016 nasabah BPR mengalami kenaikan lagi sebanyak 774 orang atau $11,31 \%$ menjadi 7.612 , pada tahun berikutnya juga mengalami kenaikan yaitu berjumlah 8.574 orang mengalami kenaikan nasabah berjumlah 962 orang atau $12,63 \%$.

Dari observasi yang dilakukan peneliti di Bank BPR, Tambah data peneliti melihat antrian nasabah yang lama. Peneliti beranggapan bahwa hal ini disebabkan oleh jumlah nasabah yang terus meningkat tidak didukung oleh jumlah teller yang melayani di Bank PD. BPR Rokan Hilir Cabang Kubu yaitu berjumlah 2 orang saja. Selain itu, peneliti juga menanyakan kepada nasabah dimana mereka mengatakan bahwa mereka telah menunggu selama lebih kurang satu jam.

$$
\text { Menurut Daryanto (2011:1), }
$$
pemasaran adalah suatu proses sosial dan manajerial dimana individu dan kelompok mendapatkan kebutuhan dan keinginan mereka dengan menciptakan, menawarkan, dan bertukar sesuatu yang bernilai satu sama lain

Menurut Kotler dan Armstrong (2012:29), menyatakan bahwa pemasaran sebagai proses dimana perusahaan menciptakan nilai bagi pelanggan dan membangun hubungan pelanggan yang kuat untuk menangkap nilai dari pelanggan sebagai imbalan

Menurut David (2011:198), "Pemasaran dapat dideskripsikan sebagai proses pendefinisian, pengantisipasian, penciptaan, serta pemenuhan kebutuhan dan keinginan konsumen akan produk dan jasa."

Dari beberapa definisi-definisi di atas, maka dapat ditarik kesimpulan bahwa pemasaran adalah proses menciptakan, mengomunikasikan, dan menyerahkan nilai yang bertujuan untuk memahami kebutuhan dan keinginan konsumen akan produk dan jasa, sehingga tercipta hubungan pelanggan yang menghasilkan penjualan

Fandy Tjiptono (2011: 164), adalah kondisi dinamis yang berhubungan dengan produk, jasa, sumber daya manusia, proses, dan lingkungan memenuhi atau melebihi harapan.

Sedangkan Ratnasari dan Aksa (2011:107), kualitas pelayanan adalah seberapa jauh perbedaan antara kenyataan dan harapan pelanggan atas pelayanan yang diterima/diperoleh.

Tjiptono (2011:59) menyatakan bahwa:"Kualisa Pelayanan jasa adalah tingkat keunggulan yang diharapkan dan pengendalian atas tingkat keunggulan tersebut untuk memenuhi keinginan pelanggan".

Menurut Lewis dan Booms (dalam Tjiptono,2012:157) menyatakan bahwa: "ukuran seberapa bagus tingkat layanan yang diberikan mampu sesuai dengan ekspektasi pelanggan.".

Goeth dan Davis yang dikutip Tjiptono (2012:51) menyatakan bahwa : “ kualitas merupakan suatu kondisi dinamis yang berhubungan dengan produk, jasa, manusia, proses, dan lingkungan yang memenuhi atau melebihi harapan."

Berdasarkan beberapa pengertian diatas yang membahas tentang kualitas pelayanan, dapat disimpulkan bahwa kualitas pelayanan adalah segala sesuatu yang diharapkan oleh konsumen agar 
perusahaan dapat memenuhi keinginan dan kebutuhan konsumen.

Tjiptono \& Chandra (2011 : 232) kualitas pelayanan terdiri dari 5 (lima) dimensi pengukuran yaitu :

1. Bukti Fisik (Tangibles)

2. Keandalan (Reliability)

3. Daya Tanggap (Responsiveness)

4. Jaminan (Assurance)

5. Empaty (Emphaty)

Pelanggan adalah seorang yang secara kontinu dan berulang kali datang kesuatu tempat yang sama untuk memuaskan keinginannya dengan memiliki suatu produk atau mendapatkan suatu saja dan membayar produk atau jasa dan membayar produk atau jasa tersebut (Lupiyoadi;2006;174).

Menurut Kotler dan Keller (2007:177) yang menyatakan bahwa kepuasan adalah perasaan senang atau kecewa seseorang yang muncul setelah membandingkan kinerja (hasil) produk yang dipikirkan terhadap kinerja ( atau hasil) yang diharapkan.

Tjiptono (2008;24), kepuasan atau ketidakpuasan pelanggan adalah respon pelanggan terhadap evaluasi ketidaksesuaian atau diskomfirmasinya yang dirasakan antara harapan sebelumnya (atau norma kerja lainnya) dan kinerja aktual produk yang dirasakan setelah pemakaiannya.

Menurut Garvin, Peppard, dan Rowland yang dikutip oleh Fandy Tjiptono (2008:25) menyatakan faktor yang sering digunakan dalam mengevaluasi kepuasan terhadap suatu produk antara lain meliputi:

a. Kinerja (performa).

b. Ciri - ciri atau keistimewaan tambahan (features)

c. Keandalan (realibility)

d. Kesesuaian dengan spesifikasi (conformance to specification).

e. Daya tahan (durability)

f. Servicability

g. Estetika

h. Kualitas yang dipersepsikan

Kotler dan Keller (2012: 140) mempertahankan pelanggan merupakan hal penting daripada memikat pelanggan. Oleh karena itu, terdapat 5 dimensi untuk mengukur kepuasan konsumen yaitu sebagai berikut.:

1. Membeli lagi;

2. Mengatakan hal-hal yang baik tentang perusahaan kepada orang lain dan merekomendasikannya;

3. Kurang memperhatikan merek dan iklan produk pesaing;

4. Membeli produk lain dari perusahaan yang sama;

5. Menawarkan ide produk atau jasa kepada perusahaan.

Kepuasaan nasabah yang semakin diyakini sebagai kunci sukses pemasaran jasa bank, tidak bisa dipisahkan darikualitas pelayanan yang diberikan oleh pihak bank. Dengan demikian, kualitas pelayanan berpengaruh positif terhadap pencapain kepuasaan nasabah. Hal ini disinyalir melalui pendapat Tjiptono (2011: 129) yang menyatakan untuk mewujudkan dan mempertahankan kepuasan pelanggan.

Dian Puspitasari, 2015, Jurnal UNRI, Pengaruh Kualitas Pelayanan Terhadap Kepuasan Nasabah (Studi Pada Bank Riau Kepri Cabang Pasir Pengaraian) Penelitian ini dilakukan di Bank Riau Kepri, cabang Pasir Pengaraian, Hasil dari. perhitungan koefisien determinasi 0,670. Artinya, kualitas layanan mempengaruhi kepuasan pelanggan sebesar $67 \%$.

Nova Uli Sinaga, 2009, Pengaruh Kualitas Pelayanan Terhadap Kepuasan Nasabah Britama Studi Kasus Pada PT. BRI (Persero) Tbk, Cabang Manado Pinaesaan. penelitian ini diadakan di. BRI (Persero) Tbk, Cabang Pinaesaan Manado, Hasil penelitian ini untuk menjawab hipotesis; Ada hubungan yang signifikan yang mempengaruhi kualitas layanan pada kepuasan pelanggan, dengan kekuatan yang signifikan menunjukkan bahwa faktor-faktor penentu kepuasan atau kepuasan pelanggan BritAma tergantung pada faktor-faktor ini sangat kuat sebanding dengan faktor lain. Hasil 
uji t atau korelasi sehingga faktor-faktor yang mempengaruhi kepuasan pelanggan BritAma signifikan pada tingkat kepercayaan.

Lorry Priska Klavert, 2015. Politeknik Negeri Manado, Pengaruh Kualitas Pelayanan Terhadap Kepuasan Nasabah Pada PT. Bank Rakyat Indonesia (Persero) Tbk. Unit Politeknik, Hasil penelitian menunjukkan bahwa dimensi kualitas pelayanan yang terdiri atas Tangible, Emphaty, Reliability, Responsiveness dan Assurance memiliki pengaruh terhadap kepuasan nasabah, Dengan demikan PT. Bank Rakyat Indonesia (Persero) Tbk. Unit Politeknik harus memperbaiki dan meningkatkan kualitas pelayanan terutama pada dimensi Emphaty dan Reliability.

\section{METODE}

Penelitian ini dilakukan pada PD. BPR Rokan Hilir Cabang Kubu Kabupaten Rokan Hilir yang berkantor pusat dijalan Jenderal Sudirman Desa Rantau Panjang Kiri Kecamatan Kubu

a. Data Primer, Data Primer yaitu data yang dikumpulkan dan diperoleh melalui pengamatan langsung di tempat penlitian dengan mengambil data yang dibutuhkan sesuai dengan penelitian berupa data hasil kuesioner, yaitu data yang diperoleh secara langsung dari PD. BPR Rokan Hilir Cabang Kubu Kabupaten Rokan Hilir memlauli kuesioner.

b. Data Sekunder, Data skunder yaitu data yang penulis peroleh dari sumber data yang ada kaitannya dengan penelitian ini berupa data yang sudah tersedia seperti data jumlah nasabah, struktur organisasi dan aktifitas organisasi serta data lainnya yang mendukung analisa dalam penelitian ini

Populasi, Menurut Sugiyono (2013:115) "Populasi adalah keseluruhan dari objek yang akan diteliti”. Adapun yang menjadi populasi dalam penelitian ini adalah seluruh nasabah PD. BPR Rokan Hilir
Cabang Kubu Kabupaten Rokan Hilir pada tahun 2017 adalah 8.574 nasabah.

Sampel, Menurut Sugiyono (2013: 116) : "Sampel adalah bagian dari jumlah dan karakteristik yang dimiliki oleh populasi tersebut". Dalam penelitian ini pengambilan sampel menggunakan teknik accidential sampling, yaitu pengambilan sampel secara aksidental (accidental) dengan mengambil kasus atau responden yang kebetulan ada atau tersedia di suatu tempat sesuai dengan konteks penelitian (Notoatmodjo, 2010:34). Populasi lebih besar dari 100, maka digunakan rumus slovin yang dikutip oleh Roni Andespa (2014:134) yaitu:

$$
\mathrm{n}=\frac{N}{1+N \mathrm{e}^{2}}
$$

Dimana :

$\mathrm{n}=$ Jumlah sampel

$\mathrm{N}=$ Jumlah populasi (nasabah tahun 2017)

Maka ukuran sampel:

$$
\begin{aligned}
& \mathrm{n}=\frac{N}{1+N \mathrm{e}^{2}}=\mathrm{n}=\frac{8.574}{1+(8.574) \cdot 10 \%^{2}}=\mathrm{n}= \\
& \quad \frac{8.574}{1+(8.574) \cdot 0,1^{2}} \mathrm{n}=\mathrm{n}=\frac{8.574}{1+85,74} \\
& \mathrm{n}=\frac{8.574}{86,74} \mathrm{n}=98,84
\end{aligned}
$$

Teknik analisa data dalam Penelitian ini adalah menggunakan deskriftip dan kuantitatif.

1. Regresi Linier Sederhana

Regresi linier sedehana digunakan untuk melihat arah hubungan antara variabel bebas terhadap variabel terikat, adapun bentuk umum persamaan regresin linier sedehana adalah $\mathrm{Y}=\mathrm{a}+\mathrm{bX}+\varepsilon$

Dimana:

$\mathrm{Y}=$ Kepuasan Nasabah

$\mathrm{X}=$ Kualitas Pelayanan

$\mathrm{a}=$ konstanta

$\mathrm{b}=$ koefrsien regresi

$\varepsilon=$ tingkat kesalahan.

\section{Uji_t}


Digunakan untuk melihat pengaruh variabel bebas terhadap variabel terikat, dengan kriteria pengujian adalah sebagai berikut $: \mathrm{H}_{0}$ Ditolak jika nilai $\mathrm{t}_{\text {_hitung }}>\mathrm{t}_{\text {_tabel. }}$. artinya ada pengaruh yang signifikan variabel bebas terhadap variabel terikat. $\mathrm{H}_{0}$ Diterima jika nilai t_hitung < $\mathrm{t}_{-}$tabel. artinya tidak ada pengaruh yang signifikan variabel bebas terhadap variabel terikat.

\section{Koefesien Determinasi}

Koefisien determinasi $\left(\mathrm{R}^{2}\right)$ dilakukan untuk melihat adanya hubungan yang sempurna atau tidak, yang ditunjukkan pada apakah perubahan variable Kualitas Pelayanan, akan diikuti oleh variabel terikat (Kepuasan pelanggan) pada proporsi yang sama. Pengujian ini dengan melihat nilai $R$ Square (R2). Nilai koefisien determinasi adalah antara 0 sampai dengan 1 . Selanjutnya nilai $\mathrm{R}^{2}$ yang kecil berarti kemampuan variabel-variabel independent dalam menjelaskan variasi variabel dependent amat terbatas. Nilai yang mendekati 1 berarti variabel-variabel independent memberikan hampir semua informasi yang dibutuhkan untuk memprediksi variasi dependent (Ghozali, 2009:56).

\section{HASIL}

Berdasarkan hasil deskriptif diperoleh bahwa untuk variabel Kepuasan Nasabah diperoleh nilai rata-rata (Mean) sebesar 40.5657 dan variabel kualitas pelayanan sebesar 39.8182 dan nilai Std. Deviation ratarata hanya sebesar 5.88523 (Kepuasan Nasabah) dan 5.95967 (5.95967). maka hal tersebut dapat disimpulkan bahwa nilai ratarata lebih besar dari nilai Std. Deviation, sehingga data sudah bersiatribusi normal.

Berdasarkan hasil kuantitatif diperoleh bahwa data sudah valid dan reliabel, yaitu sebaran data sudah sesuai dengan keadaan dilapangan.

\section{Regresi Linier Sederhana}

Hasil Regresi Linier Sederhana

\begin{tabular}{|c|l|r|r|}
\hline \multirow{2}{*}{\multicolumn{2}{|c|}{ Model }} & \multicolumn{2}{c|}{$\begin{array}{c}\text { Unstandardized } \\
\text { Coefficients }\end{array}$} \\
\cline { 3 - 4 } \multicolumn{2}{|c|}{} & \multicolumn{1}{c|}{ B } & \multicolumn{1}{c|}{ Std. Error } \\
\hline \multirow{2}{*}{1} & (Constant) & 12.353 & 2.812 \\
\cline { 2 - 4 } & Kualitas Pelayanan & .709 & .070 \\
\hline
\end{tabular}

a. Dependent Variable: Kepuasan Nasabah
Berdasarkan tabel diatas diperoleh persamaan regresi linier sederhana adalah sebagai berikut : $\mathrm{Y}=12.353+0.709 \mathrm{X}$,

Persamaan tersebut dapat diartikan sebagai berikut, Konstanta sebesar 12.353 artinya tanpa adanya Kualitas Pelayanan, atau nilai Kualitas Pelayanan $=$ nol (0) maka Kepuasan Nasabah hanya sebesar 12.353 satuan. Nilai koefisien regresi sebesar 0.709 menunjukkan jika variabel Kualitas Pelayanan meningkat sebesar 1 satuan, maka Kepuasan Nasabah akan meningkat sebesar 0.709 satuan.

Uji_t

\begin{tabular}{|} 
Hasil Uji_t \\
\begin{tabular}{|c|c|c|c|}
\hline \multicolumn{2}{|c|}{ Model } & $\mathrm{t}$ & Sig. \\
\hline \multirow{2}{*}{1} & (Constant) & 4.394 & .000 \\
\cline { 2 - 4 } & Kualitas Pelayanan & 10.145 & .000 \\
\hline
\end{tabular}
\end{tabular}

Dependent Variable: Kepuasan Nasabah

Berdasarkan hasil olah data diperoleh nilai t-hitung sebesar 10.145 sedangkan untuk nilai t_tabel diperoleh sebesar 1.98472, maka hal ini dapat dijelaskan bahwa nilai t_hitung (10.145) > dari t_tabel (1.98472), atau nilai Sig. < dari 0,50 persen sehingga dapat disimpulkan bahwa ada pengaruh yang signifikan antara Kualitas Pelayanan terhadap Kepuasan Nasabah.

\section{Koefesien Determinasi}

Koefisien determinasi menunjukkan seberapa besar pengaruh variabel bebas terhadap variabel terikat. Berikut adalah hasil output koefesien determinasi

\begin{tabular}{|l|c|r|r|}
\hline \multicolumn{1}{|c}{ Koefesien Determinasi } \\
\hline Model & $\mathrm{R}$ & R Square & Adjusted R Square \\
\hline 1 & $.717^{\mathrm{a}}$ & .515 & .510 \\
\hline
\end{tabular}

Predictors: (Constant), Kualitas Pelayanan Dependent Variable: Kepuasan Nasabah

Berdasarkan tabel diatas, maka dapat diperoleh nilai R_square atau koefesien determinasi sebesar 0.515 yang memiliki arti besarnya pengaruh variabel bebas/ Kualitas Pelayanan terhadap variabel p.ISSN: $2407-800 X \quad$ e.ISSN: $2541-4356$ 
terikat/ Kepuasan Nasabah sebesar 51.5\% sedangkan sisanya sebesar $48.5 \%$ dipengaruhi oleh variabel bebas lainnya yang tidak diamati dalam penelitian ini.

\section{PEMBAHASAN}

$\begin{array}{rcc}\text { Berdasarkan } & \text { hasil penelitian } \\ \text { diperoleh bahwa Kualitas } & \text { Pelayanan }\end{array}$ berpengaruh signifikan terhadap Kepuasan Nasabah pada PD.BPR Rokan Hilir Cabang Kubu Kabupaten Rokan Hilir, hal tersebut didukung oleh penelitian yang dilakuakn oleh Dian Puspitasari, 2015, Jurnal UNRI, Pengaruh Kualitas Pelayanan Terhadap Kepuasan Nasabah (Studi Pada Bank Riau Kepri Cabang Pasir Pengaraian) Penelitian ini dilakukan di Bank Riau Kepri, cabang Pasir Pengaraian bahwa ada pengaruh Kualitas Pelayanan berpengaruh signifikan terhadap Kepuasan. Selain itu juga sama dengan peneliti yang dilakuakan oleh Nova Uli Sinaga, 2009, Pengaruh Kualitas Pelayanan Terhadap Kepuasan Nasabah Britama Studi Kasus Pada PT. BRI (Persero) Tbk, Cabang Manado Pinaesaan. penelitian ini diadakan di. BRI (Persero) Tbk, Cabang Pinaesaan Manado, Hasil penelitian ini untuk menjawab hipotesis; Ada hubungan yang signifikan yang mempengaruhi kualitas layanan pada kepuasan pelanggan.

\section{SIMPULAN}

Berdasarkan hasil yang diperoleh, maka dapat ditarik suatu kesimpulan dalam penelitian ini, yaitu :

1. Hasil uji validitas dan reliabiltas serta hasil normalitas data sudah sesuai, yaitu sudah layak dianalisis atau digunakan dalam penelitian.

2. Hasil regresi linier sederhana memiliki arah hubungan yang positif, yaitu jika variabel bebas ditingkatkan maka variabel terikat akan mengalami peningkatan.yaitu dengan persamaan regresi nya $\mathrm{Y}=12.353+0.709 \mathrm{X}$.

3. Hasil uji_t diperoleh variabel kualitas pelayanan berpengaruh signifikan terhadap variabel kepuasan nasabah. Berdasarkan hasil olah data diproleh bahwa nilai t_hitung (10.145) > dari t_tabel (1.98472).

4. Koefisien Determinasi memiliki nilai sebesar 0.515 artinya besarnya pengaruh/sumbangan atau kontribusi yang diberikan variabel bebas terhadap variabel terikat sebesar $51.5 \%$ sedangkan sisanya sebesar $48.5 \%$ dipengaruhi oleh faktor-faktor lain yang tidak masuk dalam penelitian ini.

Adapun saran dalam penelitian ini adalah

1. Bagi perusahaan, hendaknya memperhatikan masalah fasilitas kemudahan pinjaman usaha yang ada di BPR Rokan Hilir, hal ini dikarenakan memiliki nilai rata-rata yang paling rendah, yaitu sebesar 3,88 pada varibel kualitas pelayanan.

2. Bagi karyawan, hendaknya memiliki waktu pengoperasian yang nyaman bagi nasabah, hal ini dikarenakan memiliki nilai rata-rata yang paling rendah, yaitu sebesar 3,89 pada varibel Kepuasan Nasabah .

3. Bagi peneliti berikutnya, hendaknya menambahkan jumlah variabel, hal ini disebabkan masih ada pengaruh sebesar

\section{DAFTAR RUJUKAN}

Daryanto. 2011. Manajemen Pemasaran: Sari Kuliah. Bandung: Satu Nusa.

David, Fred R,2011. Strategic

Management, Buku 1. Edisi 12 Jakarta.

Fandy, Tjiptono,(2011), Pemasaran Jasa, Bayumedia, Malang.

Ghozali, Imam. 2009. "Aplikasi Analisis Multivariate dengan Program SPSS “.Semarang : UNDIP.

Ismail. 2011. Manajemen Perbankan. Cetakan Kedua. Jakarta: Kencana. 
Kasmir. 2007.Dasar-Dasar Perbankan.PT Raja Grafindo Persada, Jakarta.

Kasmir. 2012. Bank dan Lembaga Kuangan Lainnya.Jakarta: PT. Raja Grafindo Persada.

Kasmir, 2014. Analisis Laporan Keuangan, Edisi Pertama, Cetakan Ketujuh. Jakarta: PT. Rajagrafindo Persada.

Kasmir. 2008.Bank dan Lembaga Keuangan Lainnya.Edisi Revisi 2008. Jakarta:PT.RAJAGRAFINDO PERSADA.

Kotler, Philip, 2007, Manajemen Pemasaran, Jilid 2, Edisi 12, PT Indeks., New Jersey.

Kotler, Philip and Gary Armstrong. 2008. Prinsip-prinsip Pemasaran. Edisi 12. Jilid 1. Jakarta: Erlangga.

Kotler, Philip and Gary Armstrong. 2012. Prinsip-prinsipPemasaran. Edisi 13. Jilid 1. Jakarta: Erlangga.

Kotler, Philip and Kevin Lane Keller. 2012. Marketing Management 13. New Jersey: Pearson Prentice Hall, Inc.

Kotler dan Keller. 2007. Manajemen Pemasaran. Jilid 1. Alih Bahasa oleh Benyamin Molan. Edisi 12. Jakarta: PT Indeks.

Kotler,Philip.2009. Manajemen Pemasaran, Edisi 12.Jakarta.

Lupiyoadi, dan A. Hamdani. 2006. Manajemen Pemasaran Jasa. Edisi Kedua. Jakarta; Salemba Empat.

Miller dan Leyton Tjiptono (2008, Strategi Pemasaran, Edisi 3, ANDI: Yogyakarta. Notoatmodjo, S. 2010. Metodologi Penelitian Kesehatan. Jakarta : Rineka Cipta.
Ratnasari dan Aksa (2011. Teori dan Kasus Manajeman Pemasaran Jasa. Edisi 1, Bogor : Ghalia Indonesia.

Shinta Agustina 2011. Ilmu Usahatani. Universitas Brawijaya Press, Malang.

Sugiyono, 2009, Metode Penelitian Kuantitatif, Kualitatif dan R\&D, Bandung : Alfabeta.

Sugiyono, 2013, Metodelogi Penelitian Kuantitatif, Kualitatif Dan R\&D. Bandung: ALFABETA.

Supranto, M.A.,APU. 2011. Pengukuran Tingkat Kepuasan Pelanggan Untuk Menaikkan Pangsa Pasar ( Cetakan Keempat). Jakarta : PT. Rineka Cipta.

Sutopo. 2006. Metodologi Penelitian Kualitatif.Surakarta: UNS.

Syafrizal Helmi Situmorang, 2012. Analisis Data untuk Riset Manajemen dan Bisnis. USU press. Medan.

Tjiptono \& Chandra 2011. Service, Quality and Satisfaction (ed 3). Yogyakarta. Andi.

Tjiptono, Fandy. (2008). Service Management Mewujudkan Layanan Prima (Edisi II).Yogyakarta: Andi Offset.

Tjiptono,2012, Service Management Mewujudkan Layanan Prima. Yogyakarta: CV Andi Offset.

Tjiptono;2008. Service Management Mewujudkan Layanan Prima (Edisi II). Yogyakarta: Andi Offset.

Wahjono 2010. Perilaku Organisasi Sentot Imam Wahjono. Edisi Pertama. Yogyakarta: Graha Ilmu 